\title{
Telemedicine assessment of long-term cognitive and functional status in anti-leucine-rich, glioma- inactivated 1 encephalitis
}

\author{
Nuria Sola-Valls, MD, Helena Ariño, MD, PhD, Domingo Escudero, MD, PhD, Elisabeth Solana, PhD, \\ Albert Lladó, MD, PhD, Raquel Sánchez-Valle, MD, PhD, Yolanda Blanco, MD, PhD, Albert Saiz, MD, PhD, \\ Josep Dalmau, MD, PhD, and Francesc Graus, MD, PhD
}

Neurol Neuroimmunol Neuroinflamm 2020;7:e652. doi:10.1212/NXI.0000000000000652

e652

\section{Abstract}

\section{Objective}

To assess the feasibility of a structured telephone interview examining the long-term cognitive and functional status in anti-leucine-rich, glioma-inactivated 1 (LGI1) encephalitis.

\section{Methods}

Telephone interviews were conducted with 37 patients after a median follow-up of 87 months from disease onset and 23 healthy controls matched for age and sex. Cognitive status was assessed with the telephone Mini-Mental State Examination ( $t$-MMSE) and 3 tests exploring verbal memory, fluency, and executive function. Functional status was evaluated with the Functional Activities Questionnaire and the modified Rankin Scale (mRS). Patients were classified as normal, with mild cognitive impairment (MCI), or with dementia based on cognitive and functional status. Assessment of the cognitive reserve was performed with a structured questionnaire. Logistic regression analysis was applied to identify predictors of cognitive impairment.

\section{Results}

Telephone interviews were successful in 36/37 (97\%) patients. Cognitive impairment was detected in 27 (75\%) including 17 with MCI and 10 with dementia. Eight (29\%) patients would have been misclassified using only the t-MMSE. Twenty-six (72\%) patients were functionally independent according to the mRS, but only 9 (35\%) were cognitively normal. Independent predictors for long-term cognitive impairment were a low cognitive reserve $(\mathrm{OR}=1.36,95 \%$ CI: $1.05-1.76 ; p=0.02)$ and bilateral hippocampal hyperintensity at initial MRI $(\mathrm{OR}=27.03$, 95\% CI: $1.87-390 ; p=0.02$ ).

\section{Conclusions}

Telemedicine is a feasible tool to assess the cognitive and functional outcome in patients with anti-LGI1 encephalitis. Cognitive impairment is often missed if only functional scales are used. Premorbid cognitive reserve and MRI with bilateral hippocampal hyperintensity were predictors for long-term cognitive impairment.

\author{
Correspondence \\ Dr. Graus \\ francesc.graus@idibaps.org
}




\section{Glossary}

AUC $=$ area under the curve; FAQ $=$ Functional Activities Questionnaire; LGI1 = leucine-rich, glioma-inactivated 1.

Anti-leucine-rich, glioma-inactivated 1 (LGI1) encephalitis is the second most frequent autoimmune encephalitis with an estimated annual incidence of 0.83 cases per million. ${ }^{1}$ Patients with LGI1 antibodies develop subacute onset of memory impairment, behavioral changes, and hyponatremia. The encephalitic phase is frequently preceded by a variable period where patients have isolated seizures including, among others, faciobrachial dystonic seizures. ${ }^{1,2}$ Symptoms usually respond to corticosteroids, and nearly $70 \%$ of patients have good functional recovery. However, only a third of patients return to their baseline premorbid status. ${ }^{1,3}$

Clinical assessment using only functional scales, such as the modified Rankin Scale (mRS) score, may overlook cognitive deficits that limit the return to previous activities and affect quality of life. However, studies that evaluate cognitive outcome in anti-LGI1 encephalitis are scarce and do not go beyond 2 years of follow-up. Previous research suggested that patients showed a marked impairment on memory, executive function, and processing speed at presentation, whereas some patients remained with residual deficits mainly observed on verbal memory. ${ }^{1,4-7}$ In addition, the role of premorbid cognitive reserve that probably is relevant in the recovery of elderly patients after acute neurologic events has not been previously explored in cases of anti-LGI1 encephalitis. ${ }^{8}$

Telemedicine is a novel discipline that offers high-quality patient care through numerous applications and services that facilitate a direct, cost-effective exchange of information between patients and physicians. ${ }^{9}$ In the case of rare diseases or patients' with restricted access to subspecialty care, such as autoimmune encephalitis, the use of telemedicine may be useful to assess cognitive performance in more detail over time. ${ }^{10}$

In this study, we assessed the feasibility of using a structured telephone interview to examine long-term cognitive performance and functional status of patients with anti-LGI1 encephalitis.

\section{Methods}

\section{Patients}

We reviewed all Spanish patients with anti-LGI1 encephalitis diagnosed at the Neuroimmunology laboratory of the Institut d'Investigació Biomèdica August Pi i Sunyer (IDIBAPS), Hospital Clinic (Barcelona, Spain), between September 1998 and June 2014. Patients were included if they fulfilled the following criteria: (1) age $\geq 18$ years; (2) evidence of cognitive deterioration at diagnosis demonstrated by direct patient examination by one of the authors or provided by the referring physicians through a structured written questionnaire; and (3) minimum clinical follow-up of 4 years. We initially identified 49 patients, and 37 were finally included in the study. Reasons for exclusion were death ( 7 patients, 2 of them with dementia), severe dementia that precluded the telephone interview (3), and lost to follow-up (2). All 37 patients were invited by their referring physicians to participate in the study. After the patient's agreement to participate, one of the authors contacted the patient directly to explain the goals of the study and obtain informed verbal consent, witnessed by a relative. Appointments for the structured telephone interview were scheduled according to dates and times that were convenient for patients and relatives. Information on symptom onset and main syndromes, ancillary studies, treatment response to immunotherapy, and functional outcome at 24 months was previously reported. ${ }^{3}$

\section{Telephone intervention characteristics}

Each telephone interview was performed by the same neurologist (N.S.) and lasted approximately 60 minutes. This included a structured interview with the patient about current clinical status, presence of comorbidities, ${ }^{11}$ the cognitive reserve questionnaire, and the Functional Activities Questionnaire (FAQ). Patients answered all the questions, and the answers were corroborated by a family member. The cognitive reserve questionnaire measured 8 different aspects of the premorbid intellectual activity (educational level and training courses, educational level of parents, work occupation performed throughout life, musical education, and ability to speak several languages) and cognitive-stimulating activities such as reading and practicing intellectual games (table 1). The final score was the sum of the scores for each item (maximum 25 points, best cognitive reserve). ${ }^{12}$ The FAQ is a standardized assessment of instrumental activities of daily living (11 items). Functional dependence is considered with scores $\geq 6$ points. ${ }^{13,14}$ Based on the aforementioned data, the mRS score was obtained, as this is the most widely used clinical outcome for measuring the degree of disability or dependence of patients with neurologic disability. The mRS is an ordered scale coded from 0 (no symptoms) through 5 (severe disability) and 6 (death). This scale has been shown to be reliable when obtained by telephone, and the Spanish version has been previously validated. Bad functional outcome was defined when the mRS score was $\geq 3$. ${ }^{15,16}$

Before starting the brief cognitive battery, the family member was asked to leave the room and remove any calendars, clocks, or devices that could interfere with the cognitive evaluation. The brief cognitive battery comprised the Spanish telephone version of the Mini-Mental State Examination (t-MMSE) and evaluation of 3 specific cognitive domains: verbal memory, executive function, and language. The Spanish version of the t-MMSE score ranges from 0 to 26, and cognitive impairment 
Table 1 Cognitive reserve questionnaire ${ }^{12}$

\begin{tabular}{|c|c|}
\hline Item & Points \\
\hline \multicolumn{2}{|l|}{ Educational level } \\
\hline No formal schooling & 0 \\
\hline Self-taught to read/write & 1 \\
\hline Basic (<6 years) & 2 \\
\hline Primary (>6 years) & 3 \\
\hline Secondary (>9 years) & 4 \\
\hline Higher (e.g., college and university) & 5 \\
\hline \multicolumn{2}{|l|}{ Educational level of parents (best educational level) } \\
\hline No formal schooling & 0 \\
\hline Basic or primary & 1 \\
\hline Secondary or higher & 2 \\
\hline \multicolumn{2}{|l|}{ Training courses } \\
\hline None & 0 \\
\hline 1 or 2 & 1 \\
\hline Between 2 and 5 & 2 \\
\hline More than 5 & 3 \\
\hline \multicolumn{2}{|l|}{ Work occupation outside the home } \\
\hline None & 0 \\
\hline Manual labor & 1 \\
\hline Nonmanual labor (secretarial and technical) & 2 \\
\hline Professional (requiring graduate or superior school) & 3 \\
\hline Director/executive manager & 4 \\
\hline \multicolumn{2}{|l|}{ Musical formation education } \\
\hline $\begin{array}{l}\text { No musical skills (does not play an } \\
\text { instrument or listen to music frequently) }\end{array}$ & 0 \\
\hline $\begin{array}{l}\text { Plays an instrument (amateur) or listen to music } \\
\text { frequently }\end{array}$ & 1 \\
\hline Received musical training & 2 \\
\hline \multicolumn{2}{|l|}{ Ability to speak different languages } \\
\hline Only maternal language ${ }^{a}$ & 0 \\
\hline 2 languages ${ }^{a}$ & 1 \\
\hline 1 or 2 languages ${ }^{a}+1$ foreign & 2 \\
\hline 1 or more languages ${ }^{a}+$ more than 1 foreign & 3 \\
\hline \multicolumn{2}{|l|}{ Reading skills } \\
\hline Illiterate & 0 \\
\hline Occasional (include newspapers/1 book per year) & 1 \\
\hline Between 2 and 5 books per year & 2 \\
\hline Between 5 and 10 books per year & 3 \\
\hline More than 10 books per year & 4 \\
\hline
\end{tabular}

Table 1 Cognitive reserve questionnaire ${ }^{12}$ (continued)

Item

Points

Practice of intellectual games

(chess, puzzles, and crosswords)

\begin{tabular}{ll}
\hline Never or sometimes & 0 \\
\hline Occasional (between $\mathbf{1}$ and $\mathbf{5}$ per month) & 1 \\
\hline Frequently (more than $\mathbf{5}$ per month) & 2 \\
\hline
\end{tabular}

${ }^{a}$ An officially recognized language in Spain (e.g., Spanish, Catalan, Gallego, or Euskera).

is defined when the score is $\leq 21$ points. ${ }^{17,18}$ Verbal memory was evaluated using the Free and Cued Selective Reminding Test modified from Buschke. ${ }^{19}$ Briefly, this test consists of one immediate recall task in which participants have to recall as many as 16 words (first free and then using a semantic clue) and a delayed recall task after 30 minutes. Only the delayed recall score (the sum of free and facilitated) was used for the memory index, as this score was highly correlated with the immediate recall score in our study population (list recall: rho $=0.84, p<0.001)$. Executive function was assessed using the oral Trial Making Test A and B. ${ }^{20,21}$ In this test, participants are asked to count from 1 to 25 as quickly as possible (part A) and count again, but switching between numbers and alphabet letters until 13 (part B). The final score is the time in seconds needed to complete task B. Language was explored evaluating the verbal fluency asking the participants to say as many words as possible in 1 minute from a semantic category (e.g., fruits and vegetables), and the final score was the total number of words provided.

The brief cognitive battery was initially tested in a group of 23 healthy controls to ensure the feasibility to perform it by telephone and to obtain reference values for the cognitive tests. Controls had a median age of 74 years (interquartile range $[\mathrm{IQR}], 64-80)$ and $9(39 \%)$ were male. No significant difference was observed in demographic variables or educational level between patients and healthy controls. To compare the cognitive performance across patients, raw scores from individual tests were converted to z-scores. Mild cognitive impairment (MCI) was considered when one or more cognitive domains showed a $z$-score below $-1.5 \mathrm{SD}$ of the healthy controls' distribution without interference in the activities of daily living. ${ }^{22}$ Dementia was considered when these cognitive changes had a negative impact on the activities of daily living.

At the end of the telephone interview, all participants were assessed by the Hospital Anxiety and Depression Scale (score $\geq 11$ points identified patients with mood disturbances) and the Pittsburgh Sleep Quality Index questionnaire (a score $\geq 6$ points was indicative of poor quality of sleep). ${ }^{23,24}$ Participants were also verbally assessed with the five-level version of the EuroQoL-5 dimensions instrument, which measures 
health-related quality of life. This instrument comprises the European quality (EQ) index value divided into 5 dimensions (mobility, self-care, usual activities, pain/complaints, and anxiety/depression) and the visual analog score (EQ-VAS). ${ }^{25}$

\section{Standard protocol approvals, registrations, and patient consents}

The ethics committees of the Hospital Clinic approved the study. All patients or proxies gave written informed consent for the storage and use of serum, CSF, and clinical information for research purposes. All patients and healthy controls gave consent to participate in the telephone interview.

\section{Statistics}

Descriptive statistics were computed as median (IQR) unless otherwise noted. Differences among groups based on cognitive performance were studied using the $\chi^{2}$ test and MannWhitney $U$ test as convenient, with a significance level set to $p$ $<0.05)$. Binary logistic regression was performed to identify predictors of cognitive impairment (MCI and dementia). Accuracy of the potential predictive value of clinical variables to detect patients with cognitive impairment was analyzed by the area under the curve (AUC). Statistical analyses were performed using SPSS version 25.0 (SPSS Inc, Chicago, IL) software.

\section{Data availability}

Data from the patients reported within the article are available and will be shared anonymously by request from any qualified investigator.

\section{Results}

\section{Feasibility of telephone intervention and demographic characteristics}

The telephone interview was successful in 36/37 (97\%) patients. Only one patient complained about the length of the interview before starting the brief telephone cognitive battery and did not agree to continue. Clinical and demographic features of the 36 patients are summarized in table 2. The median age at diagnosis was 65 years (IQR: $56-74$ years), and 23 (64\%) were male. At the time of diagnosis of anti-LGI1 encephalitis, patients had a median mRS score of 4 (IQR: 3-4). All patients were treated with first-line immunotherapy (steroids \pm IV immunoglobulin), and 18 (50\%) also received second-line (11) or chronic (7) immunotherapy. At 2 years, $28(78 \%)$ were functionally independent $(\mathrm{mRS}$ score $<3)$. At the last visit, 12 (33\%) patients were still on antiepileptic drugs, but only 3 patients (8\%) had experienced seizures during the preceding year.

\section{Long-term cognitive and functional status}

Long-term evaluation of patients was analyzed after a median follow-up of 87 months (IQR: 63-136 months). Patients performed significantly worse in all cognitive tests compared with healthy controls (table 3), and 27/36 (75\%) were considered to have cognitive impairment that was classified as
MCI in 17 (63\%) and dementia in 10 (37\%). The t-MMSE and the assessment of specific cognitive domains showed moderate agreement in the detection of cognitive impairment (kappa coefficient $=0.54 ; 95 \%$ CI: $0.30-0.78 ; p<0.001$ ). Nineteen of the 36 (53\%) patients were considered cognitive impaired using t-MMSE and the assessment of specific cognitive domains, and 8 (29\%) of 27 patients were classified as MCI by the brief cognitive battery despite performing well on the t-MMSE. In contrast, none of the patients who performed well in the cognitive evaluation had a low score in the t-MMSE. Patients with dementia showed worse results in executive functioning and verbal fluency compared with patients with MCI ( $p<0.001$ in both domains) (figure). Overall, the most frequently affected cognitive domain was verbal fluency $(\mathrm{N}=19,53 \%)$, followed by verbal memory ( $\mathrm{N}$ $=18,50 \%)$ and executive functioning $(\mathrm{N}=11,31 \%)$.

Patients showed higher degrees of anxiety and/or depression and worse sleep quality than healthy controls (table 2). Six (17\%) patients had symptoms of emotional distress, and 14 (39\%) referred to poor quality of sleep. Quality of life perceived by the patients was not different from that of controls with the exception of the 10 patients with dementia (median EQ-VAS score: $69 \%$ vs $80 \%$ of controls; $p=0.03$ ).

Twenty-six of the 36 patients (72\%) were considered functionally independent (FAQ $<6$ points). Eleven of them $(42.3 \%)$ were functionally normal ( $\mathrm{mRS}$ score $=0), 4$ (15.4\%) had symptoms without significant disability (mRS score $=1)$, and $11(42.3 \%)$ were independent but unable to perform premorbid activities $(\mathrm{mRS}$ score $=2)$. Despite the good functional status, 17/26 (65\%) patients had evidence of MCI. The remaining $10(28 \%)$ patients were functionally dependent $(\mathrm{FAQ} \geq 6)$ with an $\mathrm{mRS}$ score $\geq 3$, and all had dementia.

\section{Predictors of long-term cognitive outcome}

Compared with cognitively normal patients, the estimated premorbid cognitive reserve of the 27 patients with cognitive impairment was lower (median [IQR]: 9 [7-13] vs 16 [9-17] points; $p=0.02)$, more frequent bilateral hippocampal hyperintensity on initial MRI ( $67 \%$ vs $11 \%$; $p=0.009$ ), poor response to first-line treatment ( $52 \%$ vs $11 \%$; $p=0.03$ ), required second-line treatment ( $41 \%$ vs $0 \% ; p=0.02$ ), and had worse an $\mathrm{mRS}$ score at 2 years ( $\mathrm{mRS}$ score $\geq 3=70 \%$ vs $33 \%$; $p$ $=0.049$ ). No differences were observed regarding age at diagnosis, the presence of distinct clinical or paraclinical features, the delay to first-line treatment, the occurrence of relapses, or the time of follow-up. In the logistic regression analysis, including age, time of follow-up, and the existence of comorbidities as covariates, the estimated premorbid cognitive reserve $(\mathrm{OR}=1.36,95 \% \mathrm{CI}: 1.05-1.76, p=0.02)$ and the presence of bilateral hippocampal hyperintensity at the initial MRI (OR = 27.03, 95\% CI: $1.87-390, p=0.02$ ) were independent predictors for long-term cognitive impairment. In fact, an estimated premorbid cognitive reserve cutoff point of 14.5 points was able to discriminate patients who developed cognitive 
Table 2 Demographic and clinical description of 36 patients with anti-LGI1 encephalitis who completed the telephone interview

\begin{tabular}{|c|c|}
\hline Characteristics & $\begin{array}{l}\text { Anti-LGI1 encephalitis } \\
(N=36)\end{array}$ \\
\hline Male, n (\%) & $23(64)$ \\
\hline Actual age, in years, median (IQR) & $74(63-81)$ \\
\hline Age at onset, in years, median (IQR) & $65(56-74)$ \\
\hline Cognitive reserve score, median (IQR) & $11(8-14.8)$ \\
\hline \multicolumn{2}{|l|}{ Symptoms at diagnosis, $\mathbf{n}(\%)$} \\
\hline Memory deficit & $36(100)$ \\
\hline Seizures & $27(75)$ \\
\hline Faciobrachial dystonic seizures & $9(25)$ \\
\hline Mood/behavior & $28(77.8)$ \\
\hline Sleep disorders & $13(36.1)$ \\
\hline Other $^{a}$ & $5(13.9)$ \\
\hline Hyponatremia, n (\%) & 14/31 (38.9) \\
\hline \multicolumn{2}{|l|}{ MRI at disease onset, n (\%) } \\
\hline Unilateral hippocampal hyperintensity & $10(28)$ \\
\hline Bilateral hippocampal hyperintensity & $19(53)$ \\
\hline Normal & $7(19)$ \\
\hline CSF pleocytosis, n (\%) & $5(13.9)$ \\
\hline Treatment delay, in days, median (IQR) & $125(45-188)$ \\
\hline First-line immunotherapy (steroids \pm IVIG) & $36(100)$ \\
\hline Second-line immunotherapy & $11(30.6)$ \\
\hline Chronic immunotherapy & $7(19.4)$ \\
\hline Relapses, n (\%) & $12(33.3)$ \\
\hline mRS score at 24 months, median (IQR) & $2(0-2)$ \\
\hline Comorbidities $^{b}$ & $26(72)$ \\
\hline
\end{tabular}

Abbreviations: IQR = interquartile range; IVIG = IV immunoglobulin; LGI1 = leucine-rich, glioma-inactivated $1 ; \mathrm{mRS}=$ modified Rankin Scale.

a Other: daily headache $(N=1)$, anorexia $(N=1)$, hyperphagia $(N=2)$, weight loss $(N=1)$, dysautonomia $(N=2)$, and cramps in lower limbs $(N=1)$.

${ }^{b}$ Comorbidities that may have a functional impact in daily living: cardiovascular disease $(\mathrm{N}=19)$, pulmonary disease $(\mathrm{N}=2)$, endocrine disorder $(\mathrm{N}=$ $3)$, eye disorder $(\mathrm{N}=2)$, and rheumatologic disease $(\mathrm{N}=1)$.

impairment from those who did not (sensitivity 0.67 , specificity 0.89 , and accuracy AUC $=0.75,95 \% \mathrm{CI}=0.53-0.98, p=0.03$ ).

\section{Discussion}

This study shows the advantages and feasibility of using a structured telephone interview to assess the cognitive and functional status of patients who had anti-LGI1 encephalitis. Our findings show that the outcome evaluation of autoimmune encephalitis
Table 3 Results of the brief cognitive battery and related assessments obtained by telephone interview

\begin{tabular}{llll}
\hline $\begin{array}{l}\text { Test (data expressed in } \\
\text { median [IQR]) }\end{array}$ & $\begin{array}{l}\text { Patients } \\
\mathbf{( N = 3 6 )}\end{array}$ & $\begin{array}{l}\text { Healthy } \\
\text { controls } \\
\mathbf{( N = 2 3 )}\end{array}$ & $\begin{array}{l}\boldsymbol{p} \\
\text { Value }\end{array}$ \\
\hline Telephone MMSE score & $21(15-22)$ & $23(22-24)$ & 0.02 \\
\hline Verbal memory & & & \\
\hline FCSRT free delayed recall & $2.5(0-6)$ & $7(4-9)$ & 0.001 \\
\hline FCSRT total delayed recall & $7(5-11)$ & $11(8-13)$ & 0.02 \\
\hline Executive function & & & \\
\hline Oral TMT-A & 8.2 & $7.3(6.3-8.4)$ & 0.005 \\
\hline Oral TMT-B & $(7.6-10.1)$ & & 0.01 \\
\hline Verbal fluency & 60.2 & 46.6 & $(33.8-55.4)$ \\
\hline HADS score & $14.2-180)$ & $19(17-22)$ & $<0.001$ \\
\hline PSQI score & $5.5(3-9)$ & $2(0-5)$ & 0.01 \\
\hline EQ-5D-5L score & $4(3-6.5)$ & $2(2-4)$ & 0.001 \\
\hline Index value score & & & \\
\hline Quality of life, \% & $0.9(0.7-1)$ & $0.9(0.8-0.9)$ & 0.05 \\
\hline & $80(60-90)$ & $74(60-100)$ & 0.61 \\
\hline
\end{tabular}

Abbreviations: EQ-5D-5L = five-level EuroQoL 5D dimensions; FCSRT $=$ free and cued selective reminding test; HADS = Hospital Anxiety and Depression Scale; $I Q R$ = interquartile range; MMSE = Mini-Mental State Examination; PSQI = Pittsburgh Sleep Quality Index; TMT = Trial Making Test.

The Mann-Whitney $U$ test was used for statistical analysis.

only based on the mRS score is not optimal and often misses the detection of cognitive deficits. Concerning the long-term outcome of patients with anti-LGI encephalitis, we found that $75 \%$ had cognitive deficits, ranging from $\mathrm{MCI}$ to dementia, and that the estimated premorbid cognitive reserve and presence of bilateral MRI hippocampal hyperintensity at disease onset are independent predictors for long-term cognitive impairment.

The use of our structured telephone intervention provides more reliable information than that obtained only assessing the functional status according to the impression of patients' physicians or relatives, and it is particularly useful for patients with rare diseases who often come from distant geographical locations or patients whose clinical status limits follow-up visits. ${ }^{9}$ The observed moderate agreement between the t-MMSE and the cognitive battery of tests suggests that it is worth including the t-MMSE in the routine outcome assessment of autoimmune encephalitis, although it does not capture all cases with $\mathrm{MCI}$ ( $29 \%$ missed in this study). Adding the indicated cognitive battery of tests increases the length of the interview but provides relevant information on distinct cognitive functions, which may potentially be affected differently depending on the type of autoimmune encephalitis. ${ }^{26}$

As far as the evaluation of the functional status is concerned, the inclusion of the FAQ helps to confirm the mRS score. The 
Figure Comparison among the z-scores of patients with anti-leucine-rich, glioma-inactivated 1 encephalitis with normal cognitive function, mild cognitive impairment, and dementia

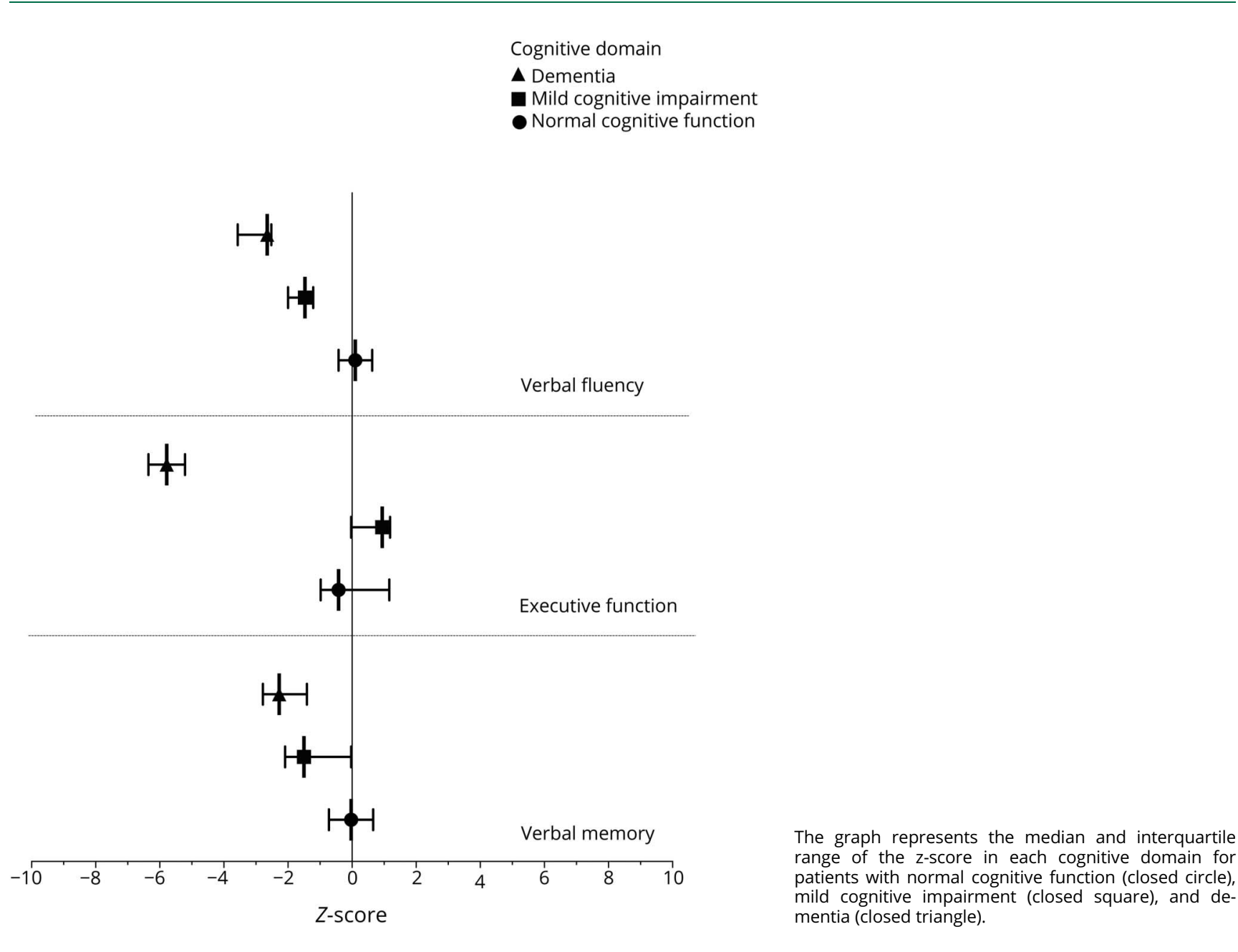

FAQ is focused on the ability to perform the activities of daily living (e.g., preparing meals or managing personal finances) that are affected at early stages of dementia development, probably before the mRS score is affected. ${ }^{27}$ Other comorbidities could affect the mRS score but not specific items of FAQ. In our study, $72 \%$ of patients had a good functional status (mRS score $<3$ ) after a median follow-up of 7 years. This figure would decrease to $67 \%$ if we include the 3 patients with severe dementia that could not carry out the interview. In any case, the frequency is similar to that reported in a Dutch series $(67 \%)^{1}$ and our own series $(71 \%)^{3}$ in which the follow-up was 2 years.

Among the 26 patients who were functionally independent, only 9 (35\%) had normal cognitive function emphasizing the need to include a formal cognitive evaluation to assess the full effect of anti-LGI1 encephalitis in patients' outcome. We detected lower scores in cognitive domains beyond memory deficits. ${ }^{5}$ A similar result, including visuospatial memory deficits, was identified in a series of 30 patients examined a median of 2 years after onset of anti-LGI1 encephalitis. ${ }^{4}$ Another series consisting of 11 patients with a good mRS score (0-2) who had neuropsychological assessment after a median of 44 months from disease onset showed that visuospatial recognition memory was the main residual deficit. ${ }^{1}$ This cognitive domain could not be assessed in our telephone interview, suggesting that the frequency of cognitive impairment could be even higher than that reported here.

Our study shows that a lower estimated premorbid cognitive reserve and the presence of bilateral MRI hippocampal hyperintensity at disease onset are 2 independent predictors of long-lasting cognitive impairment. Cognitive reserve is defined as the adaptability of cognitive processes to brain aging, pathology, or insult. It is influenced by innate individual differences and the exposure to different socio-occupational factors such as early life education, profession, leisure activities, and/or social engagement. ${ }^{28,29}$ Among several different approaches to assess cognitive reserve, we used a questionnaire that assesses a limited number of intellectual activities to ease the telephone interview, but the activities selected are among the most important. ${ }^{12}$ High cognitive reserve has been found associated with a reduced rate of cognitive decline and dementia. ${ }^{30}$ Prospective longitudinal studies of patients who developed mild cognitive impairment or Alzheimer showed that a higher 
premorbid cognitive reserve delayed the onset of cognitive decline, although this decline accelerated as soon as the symptoms of dementia started. ${ }^{31} \mathrm{~A}$ high educational level, the most commonly assessed cognitive reserve indicator, has been associated with a reduced risk of postoperative cognitive dysfunction or better cognitive outcome after traumatic brain injury. ${ }^{32,33}$ Therefore, it is likely that a high cognitive reserve also influences the outcome in patients with anti-LGI1 encephalitis.

The cognitive deficits of patients with anti-LGI1 encephalitis have been found associated with the presence of residual structural damage to the hippocampus as evaluated by MRI. ${ }^{4}$ We postulate that patients with bilateral hippocampal MRI abnormalities at disease onset probably have more brain inflammation than those with unilateral lesions or normal MRI and are at risk to eventually develop more severe hippocampal atrophy explaining the association we found with poor cognitive outcome.

Our study has several limitations. First, we used a transversal design that prevents ascertaining if the long-term cognitive changes result from the acute stage of the encephalitis or from a prolonged, albeit mild, inflammatory activity that contributes to irreversible deficits. Moreover, considering the median age of patients with anti-LGI1 encephalitis, the worsening cognitive status over time of some patients could potentially have been influenced by unrelated comorbidities (e.g., neurodegenerative processes) that were unmasked or aggravated by the autoimmune inflammatory changes. Telephone assessment could only be performed to patients with good familiar support and accessible by phone, which may limit the assessment of institutionalized patients or with advanced dementia downplaying the real impact of anti-LGI1 encephalitis in the cognitive status. Last, we could only explore the cognitive reserve by partially assessing various aspects of life experience but the concept of reserve also accounts for individual differences in susceptibility to age-related brain changes that could not be assessed in this study. ${ }^{28}$

A comprehensive evaluation of the long-term outcome of patients with anti-LGI1 encephalitis is essential for a better knowledge of the cognitive domains predominantly affected by the disease and optimal assessment of the efficacy of immunotherapies. We have demonstrated that telemedicine through a structured telephone interview is feasible and provides a good instrument to address these issues. Future studies are encouraged to confirm these results and to validate the brief cognitive battery for its standard use in the evaluation of anti-LGI1 and other autoimmune encephalitis, and it should be considered, along with the mRS, for the long-term assessment of autoimmune encephalitides.

\section{Acknowledgment}

The authors thank their colleagues for providing clinical information and allowing them to contact the patients included in the study: Inés Barceló (Hospital Universitario Son Dureta,
Palma de Mallorca); Jordi Bruna (Hospital Universitario de Bellvitge, Hospitalet); Dulce Campos (Hospital Universitario de Valladolid, Valladolid); Cesar Ramón Carbajo (Hospital Universitario Central de Asturias, Oviedo); Cristóbal Carnero (Hospital Universitario Virgen de las Nieves, Granada); Mar Carreño (Hospital Clinic, Barcelona); Esther Catena (Hospital Universitario de Bellvitge, Hospitalet); Antonio del Olmo (Hospital Universitario Doctor Peset, Valencia); Alfonso Falcon (Hospital San Pedro de Alcántara, Cáceres); Jaime Gállego (Clínica Universidad de Navarra, Pamplona); Antonio Gil-Nagel (Hospital Ruber Internacional, Madrid); Juan Francisco Gonzalo (Hospital Universitario 12 de Octubre, Madrid); Isabel Illa (Hospital de Sant Pau, Barcelona); Solange Kapetanovic (Hospital Universitario Basurto, Bilbao); Mónica Kurtis (Hospital Ruber Internacional, Madrid); Teresa Lema (Complejo Hospitalario Universitario Juan Canalejo, A Coruña); Paula Lobato (Complejo Hospitalario de Toledo, Toledo); José Luis Lopez-Sendon (Hospital Universitario Ramón y Cajal, Madrid); Mercedes Lustres (Complejo Hospitalario Cristal Piñor, Ourense); Laura Martínez (Hospital Virgen del Camino, Pamplona); Jaime Masjuan (Hospital Universitario Ramón y Cajal, Madrid); Albert Molins (Hospital Universitari Doctor Josep Trueta, Girona); Jaume Morera (Hospital Sant Vicent del Raspeig, Alacant); Alejandro Ponz (Hospital Clinico Universitario de Valencia, Valencia); Silvia Presas (Hospital Germans Trias i Pujol, Badalona); Elsa Puiggròs (Consorci Sanitari Garraf, Sant Pere de Ribes); Alejandro Quilez (Hospital Universitari Arnau de Vilanova, Lleida); Eloy Rodríguez (Hospital Universitario Marqués de Valdecilla, Santander); Sonia Santos (Hospital Clínico Universitario Lozano Blesa, Zaragoza); Carlos Vilar (Hospital General Universitario de Castellón, Castellón de la Plana); Alberto Villarejo (Hospital Universitario 12 de Octubre, Madrid); Montserrat Viñals (Hospital Universitario Reina Sofía, Córdoba). They thank Dr. Myrna Rosenfeld for critical reading of the manuscript and useful suggestions.

\section{Study funding}

This study was supported in part by Fondo de Investigaciones Sanitarias and Fondo Europeo de Desarrollo Regional (FEDER), Spain (FIS 15/00377, FG; FIS 14/00203, J.D.), NIH RO1NS077851 (J.D.), and Fundació Cellex (J.D.). N. Sola-Valls is a recipient of a Predoctoral Grant for Health Research (FI16/00251) from the Instituto de Salud Carlos III, Spain. H. Ariño is a recipient of a Rio Hortega grant (CM16/00136) from the Instituto de Salud Carlos III, Spain.

\section{Disclosure}

N. Sola-Valls received compensation for consulting services and speaker honoraria from Genzyme, Biogen, Merck Serono, and Bayer Schering. H. Ariño, D. Escudero, E. Solana, and A. Lladó report no disclosures. R. Sanchez-Valle received compensation for consulting services from Ionis Pharmaceuticals, Wave Life Sciences, and Neuraxpharm. Y. Blanco received compensation for consulting services and speaker honoraria from Merck Serono, Biogen Idec, Sanofi-Aventis, Teva, and Novartis. A. Saiz received compensation for consulting 
services and speaker honoraria from Bayer Schering, Merck Serono, Biogen Idec, Sanofi-Aventis, Teva, Novartis, and Roche. J. Dalmau receives royalties from Athena Diagnostics for the use of $\mathrm{Ma} 2$ as an autoantibody test and from Euroimmun for the use of NMDA, GABAB receptor, GABAA receptor, DPPX and IgLON5 as autoantibody tests. He is editor for Neurology: Neuroimmunology \& Neuroinflammation. F. Graus receives royalties from Euroimmun for the use of IgLON5 as an autoantibody test and honoraria for Assistant Editor of MedLink Neurology. Go to Neurology.org/NN for full disclosures.

\section{Publication history}

Received by Neurology: Neuroimmunology \& Neuroinflammation September 3, 2019. Accepted in final form November 19, 2019.

\section{Appendix Authors}

\begin{tabular}{|c|c|c|c|}
\hline Name & Location & Role & Contribution \\
\hline $\begin{array}{l}\text { Nuria } \\
\text { Sola-Valls, } \\
\text { MD }\end{array}$ & $\begin{array}{l}\text { Hospital Clínic, and } \\
\text { Institut d'Investigació } \\
\text { Biomèdica August Pi i } \\
\text { Sunyer (IDIBAPS), } \\
\text { Barcelona, Spain }\end{array}$ & Author & $\begin{array}{l}\text { Designed and } \\
\text { conceptualized the } \\
\text { study; analyzed the } \\
\text { data; statistical } \\
\text { analysis of data; } \\
\text { drafted the first } \\
\text { version of the } \\
\text { manuscript; and } \\
\text { revised the manuscript } \\
\text { for intellectual content }\end{array}$ \\
\hline
\end{tabular}

\begin{tabular}{|c|c|c|c|}
\hline $\begin{array}{l}\text { Helena } \\
\text { Ariño, } \\
\text { MD, PhD }\end{array}$ & $\begin{array}{l}\text { IDIBAPS, Barcelona, } \\
\text { Spain }\end{array}$ & Author & $\begin{array}{l}\text { Acquisition of clinical } \\
\text { data; analysis and } \\
\text { interpretation of the } \\
\text { data; and revised the } \\
\text { manuscript for } \\
\text { intellectual content }\end{array}$ \\
\hline $\begin{array}{l}\text { Domingo } \\
\text { Escudero, } \\
\text { MD, PhD }\end{array}$ & $\begin{array}{l}\text { Hospital Clínic and } \\
\text { IDIBAPS, Barcelona, } \\
\text { Spain }\end{array}$ & Author & $\begin{array}{l}\text { Acquisition of clinical } \\
\text { data; analysis and } \\
\text { interpretation of the } \\
\text { data; and revised the } \\
\text { manuscript for } \\
\text { intellectual content }\end{array}$ \\
\hline $\begin{array}{l}\text { Elisabeth } \\
\text { Solana, } \\
\text { PhD }\end{array}$ & $\begin{array}{l}\text { IDIBAPS, Barcelona, } \\
\text { Spain }\end{array}$ & Author & $\begin{array}{l}\text { Acquisition of clinical } \\
\text { data; analysis and } \\
\text { interpretation of the } \\
\text { data; and revised the } \\
\text { manuscript for } \\
\text { intellectual content }\end{array}$ \\
\hline
\end{tabular}

\begin{tabular}{|c|c|c|c|}
\hline $\begin{array}{l}\text { Albert } \\
\text { Lladó, } \\
\text { MD, PhD }\end{array}$ & $\begin{array}{l}\text { Hospital Clínic and } \\
\text { IDIBAPS, Barcelona, } \\
\text { Spain }\end{array}$ & Author & $\begin{array}{l}\text { Designed and } \\
\text { conceptualized the } \\
\text { study; analyzed the } \\
\text { data; acquisition of } \\
\text { clinical data; analysis } \\
\text { and interpretation of } \\
\text { the data; and revised } \\
\text { the manuscript for } \\
\text { intellectual content }\end{array}$ \\
\hline
\end{tabular}

\begin{tabular}{|c|c|c|c|}
\hline $\begin{array}{l}\text { Raquel } \\
\text { Sanchez- } \\
\text { Valle, MD, } \\
\text { PhD }\end{array}$ & $\begin{array}{l}\text { Hospital Clínic and } \\
\text { IDIBAPS, Barcelona. } \\
\text { Spain }\end{array}$ & Author & $\begin{array}{l}\text { Designed and } \\
\text { conceptualized the } \\
\text { study; analyzed the } \\
\text { data; acquisition of } \\
\text { clinical data; analysis } \\
\text { and interpretation of } \\
\text { the data; and revised } \\
\text { the manuscript for } \\
\text { intellectual content }\end{array}$ \\
\hline
\end{tabular}

Appendix (continued)

\begin{tabular}{|c|c|c|c|}
\hline Name & Location & Role & Contribution \\
\hline $\begin{array}{l}\text { Yolanda } \\
\text { Blanco, } \\
\text { MD, PhD }\end{array}$ & $\begin{array}{l}\text { Hospital Clínic and } \\
\text { IDIBAPS, Barcelona, } \\
\text { Spain }\end{array}$ & Author & $\begin{array}{l}\text { Acquisition of clinical } \\
\text { data; analysis and } \\
\text { interpretation of the } \\
\text { data; and revised the } \\
\text { manuscript for } \\
\text { intellectual content }\end{array}$ \\
\hline
\end{tabular}

\begin{tabular}{|c|c|c|c|}
\hline $\begin{array}{l}\text { Albert } \\
\text { Saiz, MD, } \\
\text { PhD }\end{array}$ & $\begin{array}{l}\text { Hospital Clínic and } \\
\text { IDIBAPS, Barcelona, } \\
\text { Spain }\end{array}$ & Author & $\begin{array}{l}\text { Acquisition of clinical } \\
\text { data; analysis and } \\
\text { interpretation of the } \\
\text { data; and revised the } \\
\text { manuscript for } \\
\text { intellectual content }\end{array}$ \\
\hline
\end{tabular}

\begin{tabular}{|c|c|c|c|}
\hline $\begin{array}{l}\text { Josep } \\
\text { Dalmau, } \\
\text { MD, PhD }\end{array}$ & $\begin{array}{l}\text { Hospital Clínic, ICREA } \\
\text { Barcelona, Spain and } \\
\text { University of }\end{array}$ & Author & $\begin{array}{l}\text { Acquisition of clinical } \\
\text { data; review of clinical } \\
\text { data; drafted the first }\end{array}$ \\
\hline
\end{tabular}

Pennsylvania, PA, USA version of the manuscript; revised the manuscript for intellectual content; and obtained funding

\begin{tabular}{|c|c|c|c|}
\hline $\begin{array}{l}\text { Francesc } \\
\text { Graus, } \\
\text { MD, PhD }\end{array}$ & $\begin{array}{l}\text { IDIBAPS, Barcelona, } \\
\text { Spain }\end{array}$ & Author & $\begin{array}{l}\text { Designed and } \\
\text { conceptualized the } \\
\text { study; acquisition of } \\
\text { clinical data; review of } \\
\text { clinical data; analysis } \\
\text { and interpretation of } \\
\text { the data; revised the } \\
\text { manuscript for } \\
\text { intellectual content; } \\
\text { obtained funding; and } \\
\text { wrote the final version }\end{array}$ \\
\hline
\end{tabular}

\section{References}

1. van Sonderen A, Thijs RD, Coenders EC, et al. Anti-LGIl encephalitis: clinical syndrome and long-term follow-up. Neurology 2016;87:1449-1456.

2. Irani SR, Michell AW, Lang B, et al. Faciobrachial dystonic seizures precede Lgil antibody limbic encephalitis. Ann Neurol 2011;69:892-900.

3. Ariño H, Armangué T, Petit-Pedrol M, et al. Anti-LGI1-associated cognitive impairment: presentation and long-term outcome. Neurology 2016;87:759-765.

4. Finke C, Prüss H, Heine J, et al. Evaluation of cognitive deficits and structural hippocampal damage in encephalitis with leucine-rich, glioma-inactivated 1 antibodies. JAMA Neurol 2017;74:50-59.

5. Bettcher BM, Gelfand JM, Irani SR, et al. More than memory impairment in voltagegated potassium channel complex encephalopathy. Eur J Neurol 2014;21:1301-1310.

6. Butler CR, Miller TD, Kaur MS, et al. Persistent anterograde amnesia following limbic encephalitis associated with antibodies to the voltage-gated potassium channel complex. J Neurol Neurosurg Psychiatry 2014;85:387-391.

7. Dodich A, Cerami C, Iannaccone S, et al. Neuropsychological and FDG-PET profiles in VGKC autoimmune limbic encephalitis. Brain Cogn 2016;108:81-87.

8. Roldan-Tapia MD, Canovas R, Leon I, Garcia-Garcia J. Cognitive vulnerability in aging may be modulated by education and reserve in healthy people. Front Aging Neurosci 2017;9:340.

9. Wechsler LR, Tsao JW, Levine SR, et al. Teleneurology applications: report of the telemedicine work group of the American Academy of Neurology. Neurology 2013;80:670-676.

10. Wadsworth HE, Dhima K, Womack KB, et al. Validity of teleneuropsychological assessment in older patients with cognitive disorders. Arch Clin Neuropsychol 2018; 33:1040-1045.

11. Bunn F, Burn AM, Goodman C, et al. Comorbidity and dementia: a scoping review of the literature. BMC Med 2014;12:192.

12. Rami L, Valls-Pedret C, Bartres-Faz D, et al. Cognitive reserve questionnaire. Scores obtained in a healthy elderly population and in one with Alzheimer's disease. Rev Neurol 2011;52:195-201.

13. Pfeffer RI, Kurosaki TT, Harrah CH Jr, Chance JM, Filos S. Measurement of functional activities in older adults in the community. J Gerontol 1982;37: 323-329.

14. Teng E, Becker BW, Woo E, Knopman DS, Cummings JL, Lu PH. Utility of the functional activities questionnaire for distinguishing mild cognitive impairment from very mild Alzheimer disease. Alzheimer Dis Assoc Dis 2010;24:348-353.

15. Savio K, Pietra GL, Oddone E, Reggiani M, Leone MA. Reliability of the modified Rankin Scale applied by telephone. Neurol Int 2013;5:e2.

16. Bruno A, Sethuraman S, Sedler MJ, et al. First application of a Spanish version simplified modified Rankin Scale questionnaire. Int J Stroke 2019;14:NP12. 
17. Garre-Olmo J, Lax-Pericall C, Turro-Garriga $\mathrm{O}$, et al. Adaptation and convergent validity of a telephone-based Mini-Mental State Examination. Med Clin (Barc) 2008;131:89-95.

18. Newkirk LA, Kim JM, Thompson JM, Tinklenberg JR, Yesavage JA, Taylor JL. Validation of a 26-point telephone version of the Mini-Mental State Examination. J Geriatr Psychiatry Neurol 2004;17:81-87.

19. Buschke H. Cued recall in amnesia. J Clin Neuropsychol 1984;6:433-440.

20. Mrazik M, Millis S, Drane DL. The oral trail making test: effects of age and concurrent validity. Arch Clin Neuropsychol 2010;25:236-243.

21. Kaemmerer T, Riordan P. Oral adaptation of the trail making test: a practical review. Appl Neuropsychol Adult 2016;23:384-389.

22. Albert MS, DeKosky ST, Dickson D, et al. The diagnosis of mild cognitive impairment due to Alzheimer's disease: recommendations from the National Institute on AgingAlzheimer's Association workgroups on diagnostic guidelines for Alzheimer's disease. Alzheimers Dement 2011;7:270-279.

23. Zigmond AS, Snaith RP. The hospital anxiety and depression scale. Acta Psychiatr Scand 1983;67:361-370.

24. Buysse DJ, Reynolds CF III, Monk TH, Berman SR, Kupfer DJ. The Pittsburgh Sleep Quality Index: a new instrument for psychiatric practice and research. Psychiatry Res 1989;28:193-213.

25. Devlin NJ, Brooks R. EQ-5D and the EuroQol group: past, present and future. Appl Health Econ Health Pol 2017;15:127-137.
26. Hébert J, Day GS, Steriade C, Wennberg RA, Tang-Wai DF. Long-term cognitive outcomes in patients with autoimmune encephalitis. Can J Neurol Sci 2018;45: 540-544.

27. Teng E, Becker BW, Woo E, Cummings JL, Lu PH. Subtle deficits in instrumental activities of daily living in subtypes of mild cognitive impairment. Dement Geriatr Cogn Disord 2010;30:189-197.

28. Stern Y. Cognitive reserve in ageing and Alzheimer's disease. Lancet Neurol 2012;11: 1006-1012.

29. Stern Y, Arenaza-Urquijo EM, Bartres-Faz D, et al. Whitepaper: defining and investigating cognitive reserve, brain reserve, and brain maintenance. Alzheimers Dement Epub 2018 Sep 14.

30. Matyas N, Keser Aschenberger F, Wagner G, et al. Continuing education for the prevention of mild cognitive impairment and Alzheimer's-type dementia: a systematic review and overview of systematic reviews. BMJ Open 2019;9:e027719.

31. van Loenhoud AC, van der Flier WM, Wink AM, et al. Cognitive reserve and clinical progression in Alzheimer disease: a paradoxical relationship. Neurology 2019;93: e334-e346.

32. Feinkohl I, Winterer G, Spies CD, Pischon T. Cognitive reserve and the risk of postoperative cognitive dysfunction. Dtsch Arztebl Int 2017;114:110-117.

33. Bigler ED, Stern Y. Traumatic brain injury and reserve. Handb Clin Neurol 2015;128: $691-710$ 


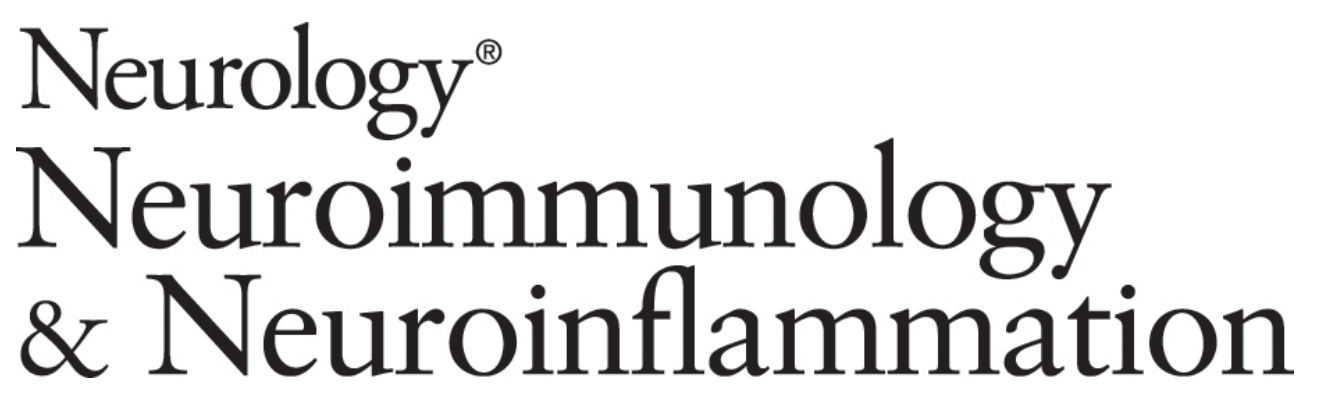

Telemedicine assessment of long-term cognitive and functional status in anti-leucine-rich, glioma-inactivated 1 encephalitis

Nuria Sola-Valls, Helena Ariño, Domingo Escudero, et al.

Neurol Neuroimmunol Neuroinflamm 2020;7;

DOI 10.1212/NXI.0000000000000652

This information is current as of December 17, 2019

Neurol Neuroimmunol Neuroinflamm is an official journal of the American Academy of Neurology.

Published since April 2014, it is an open-access, online-only, continuous publication journal. Copyright

Copyright $\odot 2019$ The Author(s). Published by Wolters Kluwer Health, Inc. on behalf of the American

Academy of Neurology.. All rights reserved. Online ISSN: 2332-7812.

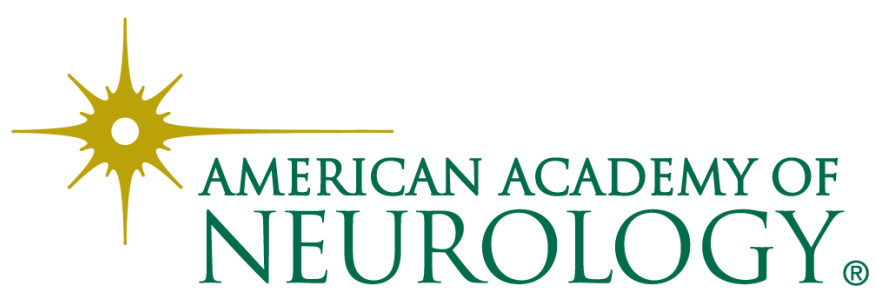




\section{Updated Information \& Services}

References

Citations

Subspecialty Collections

Permissions \& Licensing

Reprints including high resolution figures, can be found at: http://nn.neurology.org/content/7/2/e652.full.html

This article cites 32 articles, 1 of which you can access for free at: http://nn.neurology.org/content/7/2/e652.full.html\#\#ref-list-1

This article has been cited by 1 HighWire-hosted articles: http://nn.neurology.org/content/7/2/e652.full.html\#\#otherarticles

This article, along with others on similar topics, appears in the following collection(s):

All Clinical Neurology

http://nn.neurology.org//cgi/collection/all_clinical_neurology Assessment of cognitive disorders/dementia

http://nn.neurology.org//cgi/collection/assessment_of_cognitive_disord ers_dementia

Autoimmune diseases

http://nn.neurology.org//cgi/collection/autoimmune_diseases

Encephalitis

http://nn.neurology.org//cgi/collection/encephalitis

Neuropsychological assessment

http://nn.neurology.org//cgi/collection/neuropsychological_assessment

Information about reproducing this article in parts (figures,tables) or in its entirety can be found online at:

http://nn.neurology.org/misc/about.xhtml\#permissions

Information about ordering reprints can be found online:

http://nn.neurology.org/misc/addir.xhtml\#reprintsus

Neurol Neuroimmunol Neuroinflamm is an official journal of the American Academy of Neurology.

Published since April 2014, it is an open-access, online-only, continuous publication journal. Copyright

Copyright $\odot 2019$ The Author(s). Published by Wolters Kluwer Health, Inc. on behalf of the American

Academy of Neurology.. All rights reserved. Online ISSN: 2332-7812.

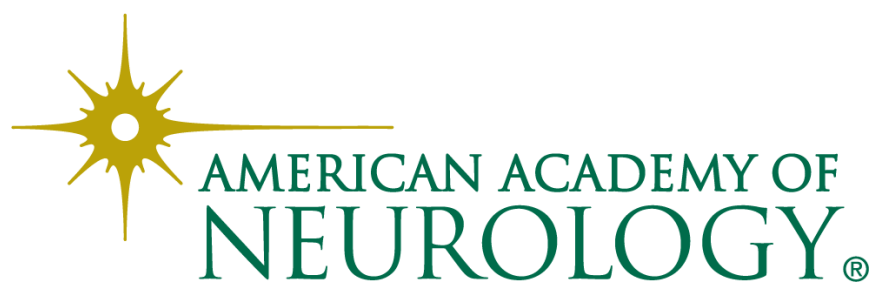

